\title{
MECHANICAL PRE-TREATMENT FOR SEPARATION OF BIO-WASTE FROM MUNICIPAL SOLID WASTE: CASE STUDY OF DISTRICT IN LATVIA
}

\author{
Dace Arina ${ }^{1}$, Janis Kalnacs ${ }^{1}$, Ruta Bendere ${ }^{2}$, Aleksandrs Murasovs ${ }^{1}$ \\ ${ }^{1}$ Institute of Physical Energetics, Latvia; ${ }^{2}$ University of Latvia, Latvia \\ dace.arina@gmail.com,jkalnacs@edi.lv, bendere@edi.lv
}

\begin{abstract}
The mechanical pre-treatment technologies are one of the solutions that are planned to be used in all waste management regions to separate biodegradable municipal waste in Latvia, thus inter alia contributing to implementation of the waste policy of the European Union. In Latvia recent research of the collected household waste composition shows that average bio-waste is $39 \%$. The article provides the results of experimental work for partly sorted municipal solid waste mechanical pre-treatment in Latvia. The goal is to detect the composition of sorted waste parts after separation by the drum screener for evaluation of the effectiveness of the mechanical pre-treatment. The experimental truckloads of the collected waste (bio-waste and partly sorted) were selected from the apartments in Broceni town during a period of one year (2017/2018). Each truckload was weighed and the mass balance of the materials was established. Mechanical pre-treatment equipment is the bag breaker, drum screener and magnetic separator. Samples were taken from partly sorted municipal solid waste in two fractions coarse, fine. The composition was determined manually in 11 parts. The moisture of fractions was determined. Results - fine fraction is $\sim 34 \%$, coarse fraction $\sim 65 \%$ and metal $\sim 1 \%$; separation of biological waste at source variates from $62 \%$ in the autumn to $17 \%$ in the spring season by mass.
\end{abstract}

Keywords: waste, composition, pre-treatment, screener, bio-waste.

\section{Introduction}

The National Waste Management Plan for 2013-2020 has set relatively high implementation objectives for the separate collection of organic waste, recycling and landfill. The European Union Directive 1999/31/EC on the landfill of waste requires ensure that until 2020 the biodegradable municipal waste disposed at the landfills must be reduced to $35 \%$ of the total amount (by weight) of biodegradable municipal waste produced in 1995 in Latvia. A problem for the national waste management is to recycle as much as $50 \%$ of household waste until 2020 according to the requirement under the European Parliament Directive 2008/98/EC on waste. One of the solutions is to implement household sorting in all regions of Latvia, but the easiest way, which was used in the country, was to organize municipal waste sorting by mechanical waste sorting technologies before their landfilling. There are the benefits of collecting food waste separately from the unsorted waste or refuse stream [1]:

- contributing to targets for diverting biodegradable waste from landfill;

- improving recycling rates;

- reducing waste disposal costs as landfill costs increase;

- reducing environmental impacts associated with landfill (toxicity in leachate, landfill gas emissions, etc.);

- reducing greenhouse gas emissions by removing the putrescent content from landfill sites;

- production of compost and liquid fertilisers for use as soil improvers;

- generation of heat and power through anaerobic digestion (AD) linked to combined heat and power plant or through use as a direct fuel.

Bio-mechanical treatment in European countries is mainly used for reduction of active biomass in the waste [2] or for stabilization of the landfill site [3] by more compacted mass after mechanical shredding. How efficient mechanical pre-treatment technologies are to sort out useful secondary materials was investigated by Meirhofer et al. [4], improving sorting schemas with spectral sensors in Austria.

The development of waste treatment requires an understanding of the characteristics of waste streams. Regular surveys of composition of municipal solid waste (MSW) have not been conducted in Latvia. The last research [5] of the household waste composition after its collection shows that the average waste composition has been: bio-waste $-39 \%$; paper $-8 \%$; plastic $-13 \%$; glass $-9 \%$; metal $-3 \%$; fine $-12 \%$; other $-16 \%$. The previous sorting activities in Broceni municipality [6] show that the local waste composition has been: bio-waste $-34 \%$; paper $-10 \%$; plastic $-11 \%$; glass 
$-6 \%$; metal $-4 \%$; fine $-27 \%$; other $-8 \%$, These data are rather similar to the data for Latvia`s average data of the morphological composition of waste. The comparison of these results is made with the obtained data on automatic sorting lines and it is presented in this article, showing the possibility to sort out some components as well as bio mass. As it has not been researched before in Latvia, the article also provides new data of the morphological composition of waste fractions after pre-treatment of household waste with reduced amount of bio-waste.

\section{Materials and methods}

Tests were performed from October 2017 until October 2018 for assessment of the morphological composition (MC) of fine fraction of MSW in Vibsteri (Fig. 1) waste sorting and transfer station (Viduskurzeme waste management organization). Each representative truckload was weighed and the mass balance of the materials was established. The sorting line is equipped with a shredder/bag opener, screener and magnetic separator of metal. The rotary drum (or trammel) screener is the model of Technobalt DS-6000 with the screen size: $60 \times 60 \mathrm{~mm}$. After the sorting lines, two fractions were received - coarse fraction and fine fraction. The morphological composition of the fine fraction ( $<60 \mathrm{~mm}$ ) was provided manually - sorted by type and weighed. The following scales were used: Svarstykliu pasaulis platform scale XK3190-A12 (precision $20 \mathrm{~g}$ ) and Scaltec Instruments SPO 61 (precision $0.1 \mathrm{~g}$ ).

12 samples were taken from partly sorted municipal solid waste with low content of bio-waste part of bio-waste (kitchen and green waste) is separated at the source. A sieve/table (size of holes $10 \times 10 \mathrm{~mm}$ ) was used to determine the small particles. The sampling for the fine fraction was carried out according to the Standards LVS CEN/TR 15310-(1-5): 2007 and LVS EN 14899:2011.

The composition was determined manually in 11 parts - paper and cardboard (soft paper, journals, packing, wallpaper); plastic (soft and hard plastic); bio- waste (kitchen waste, garden waste); small particles ( $<10 \mathrm{~mm}$, sand and miscellaneous small particles); hygiene (diapers and pads); textile (fabric); rubber and leather; wood; metal (ferrous, non-ferrous); glass; mineral (stones, ceramics). The collected data were processed with statistical software SPSS Statistics. The moisture content of the fine fraction was determined according to LVS EN 15414-3:2011 within the laboratory of the Institute of Physical Energetics.

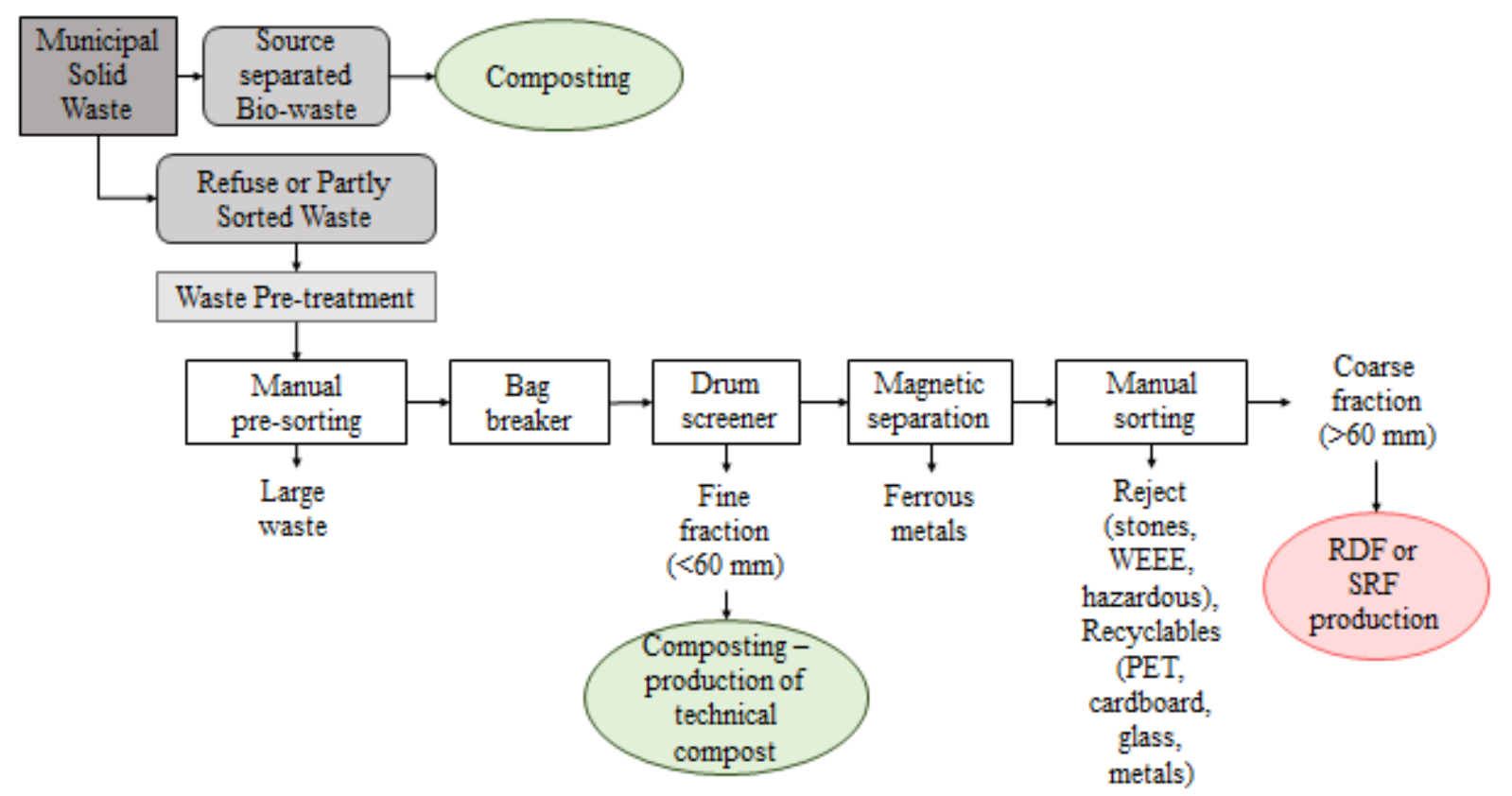

Fig. 1. Simplified scheme of waste pre-treatment 


\section{Results and discussion}

The results obtained present the content of mechanically pre-treated MSW. Each representative sample was approximately 2 tonnes. As a result of the research it was evaluated that average mass of bio-waste collected at the source formed $62 \%$ of the total collected MSW in the autumn season, $46 \%$ in the winter season, $17 \%$ in the spring season and $46 \%$ in the summer season (containing 10-14\% additions of other waste). The rest of MSW, collected as refuse or partly sorted waste, were sorted by the pre-treatment line. The results of the flow diagram of waste materials are given in Fig.2-5.

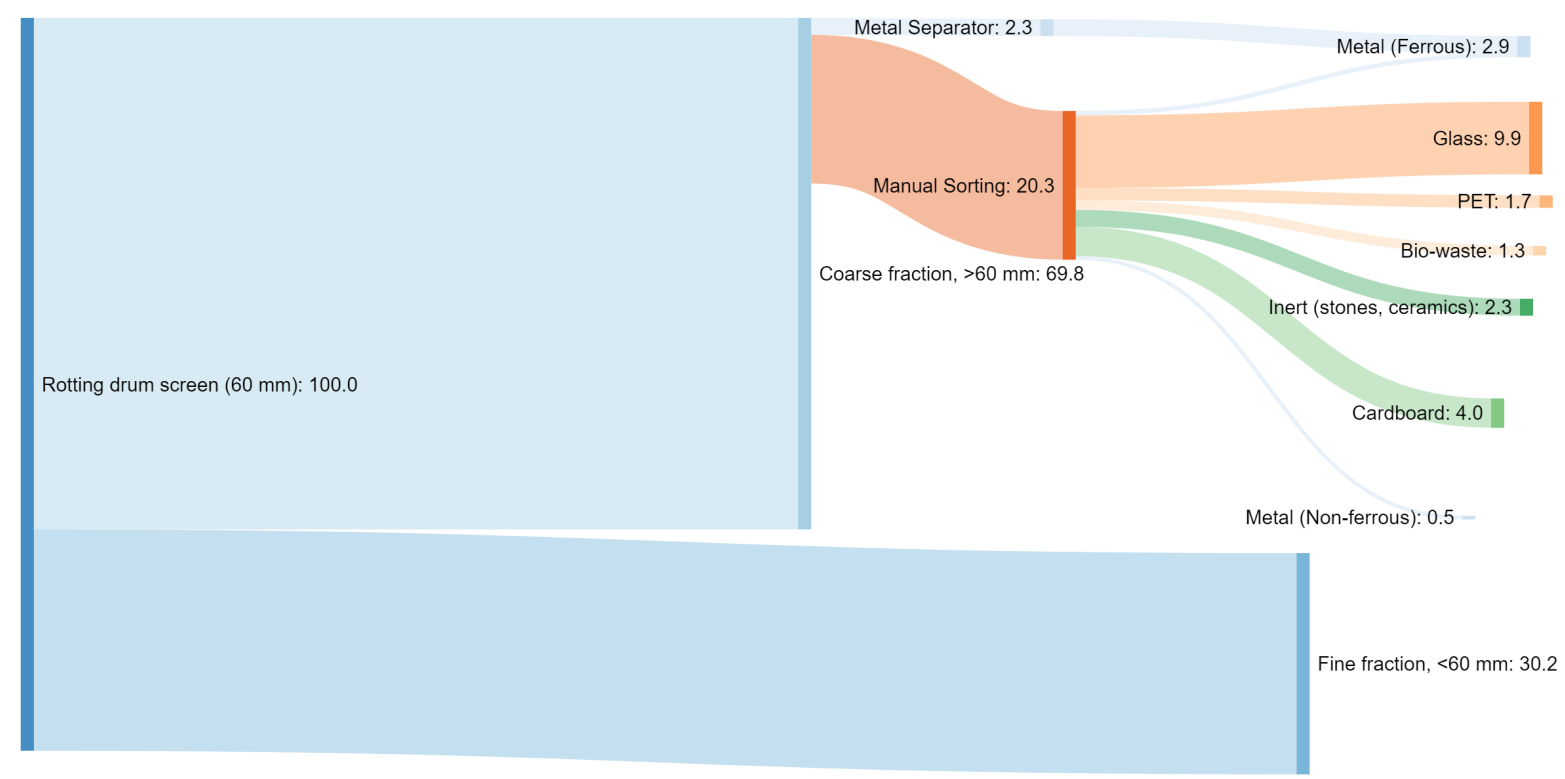

Fig. 2. Flow diagram of municipal solid waste in autumn season ( \%, mass)

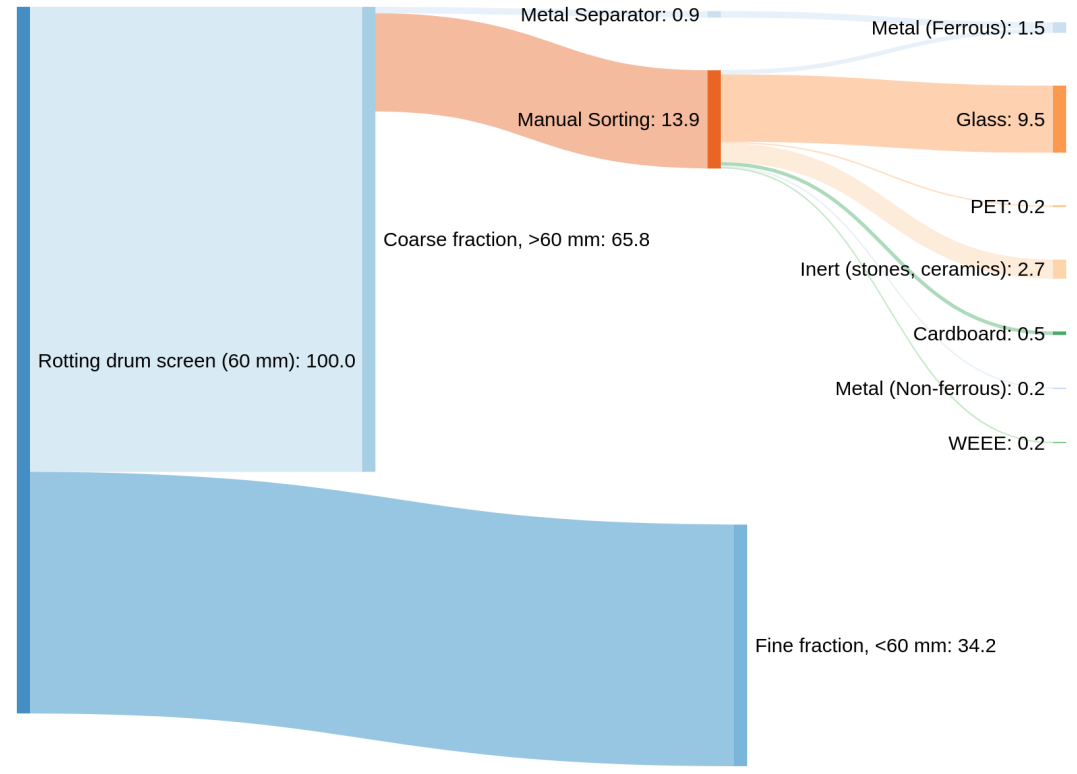

Fig. 3. Flow diagram of municipal solid waste in winter season ( \%, mass)

The experimental data show that the coarse fraction has the largest waste mass in all seasons. These data of waste fractions after mechanical pre-treatment were compared to the previous research results in the same area in summer for non-sorted municipal waste [6] (coarse fraction - $53 \%$, fine fraction $-45 \%$ and metal fraction $-2 \%$ ). It can be seen that the fine fraction is less in this research (30\%) compared to the previous (45\%). The results are comparable as waste is sampled from the same collection route in the same municipality with a similar economic status as in the previous period.

The average percentage distribution of the fine fraction content is shown in Table 1 and 2. 


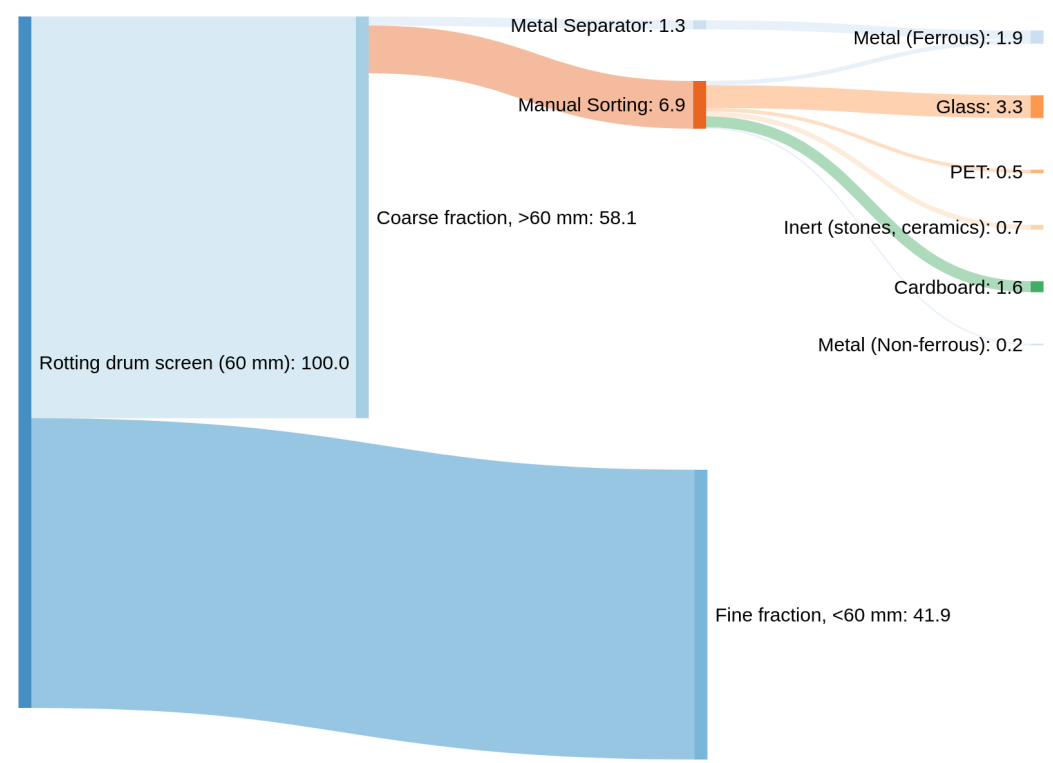

Fig. 4. Flow diagram of municipal solid waste in spring season ( \%, mass)

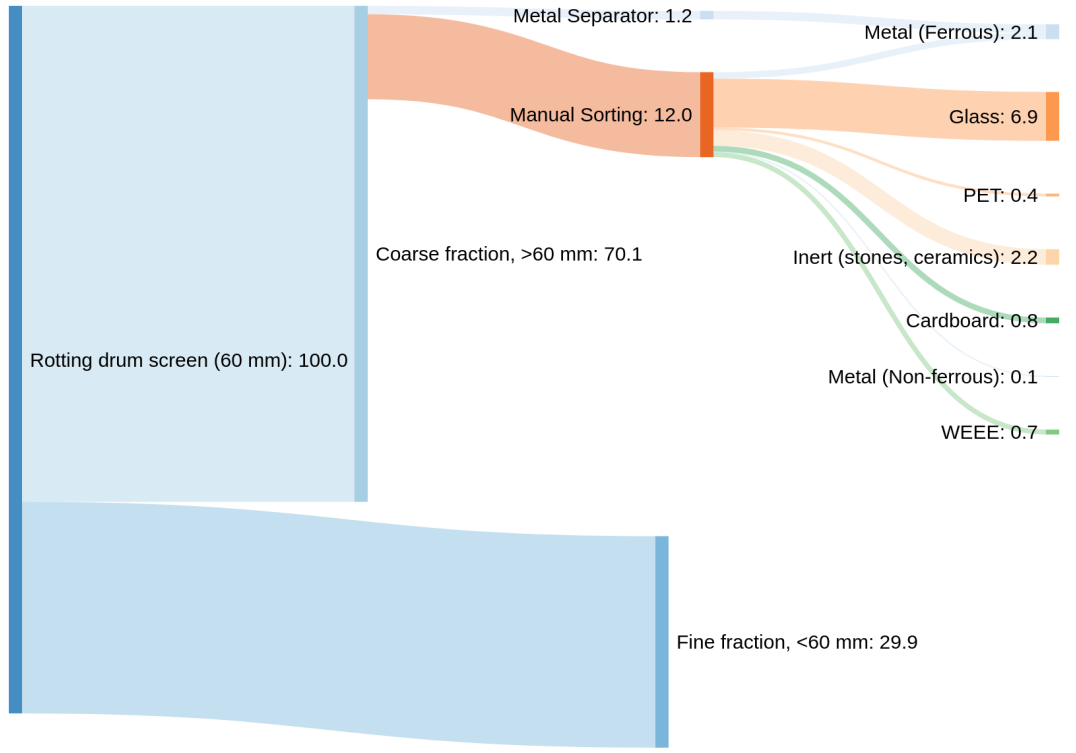

Fig. 5. Flow diagram of municipal solid waste in summer season ( \%, mass)

Table 1

Average composition (Mean \pm Std. Error) of fine fraction $(<60 \mathrm{~mm})$ of municipal solid waste after waste pre-treatment in four seasons (\%, mass)

\begin{tabular}{|c|c|c|c|c|}
\hline Content of Waste & Autumn & Winter & Spring & Summer \\
\hline Paper and cardboard & $59.4 \pm 10.03$ & $45.7 \pm 16.50$ & $15.7 \pm 4.49$ & $21.7 \pm 6.85$ \\
\hline Plastic & $4.5 \pm 0.68$ & $8.0 \pm 3.04$ & $3.9 \pm 1.15$ & $7.7 \pm 0.44$ \\
\hline Bio-waste & $19.1 \pm 4.11$ & $27.0 \pm 8.29$ & $32.0 \pm 3.42$ & $35.1 \pm 2.17$ \\
\hline Small particles & $1.5 \pm 0.23$ & $1.9 \pm 0.29$ & $14.7 \pm 4.54$ & $15.6 \pm 2.72$ \\
\hline Hygiene (diapers and pads) & $9.0 \pm 4.93$ & $9.4 \pm 8.45$ & $1.6 \pm 1.06$ & $2.3 \pm 0.62$ \\
\hline Textile & $1.7 \pm 1.66$ & $3.4 \pm 3.18$ & $1.1 \pm 0.67$ & $1.1 \pm 1.03$ \\
\hline Rubber, leather & $1.2 \pm 1.23$ & $0.0 \pm 0.00$ & $0.1 \pm 0.13$ & $0.2 \pm 0.16$ \\
\hline Wood & $1.1 \pm 1.10$ & $0.0 \pm 0.00$ & $0.2 \pm 0.17$ & $0.1 \pm 0.10$ \\
\hline Metal & $1.2 \pm 0.82$ & $0.7 \pm 0.34$ & $2.5 \pm 0.61$ & $2.3 \pm 1.22$ \\
\hline Glass & $1.4 \pm 0.63$ & $3.4 \pm 0.30$ & $10.8 \pm 1.46$ & $9.4 \pm 1.94$ \\
\hline Mineral & $0.0 \pm 0.00$ & $0.5 \pm 0.47$ & $17.5 \pm 5.71$ & $4.5 \pm 2.27$ \\
\hline
\end{tabular}


The results show that small particle waste is significantly more in spring and summer. It can be explained by intense cleaning of the area after the winter season, and therefore the waste contains waste from streets, especially sand and small stones. And in summer small bio-waste, too.

Table 2

\section{Average composition of fine fraction $(<60 \mathrm{~mm})$ of municipal solid waste after waste pre-treatment $(\%$, mass $) *$}

\begin{tabular}{|c|c|c|c|c|c|}
\hline Content of Waste & Mean \pm Std. Error & Std. Deviation & Min & Max & Variance \\
\hline Paper and cardboard & $35.6 \pm 6.97$ & 24.15 & 9.8 & 78.2 & 582.67 \\
\hline Plastic & $6.0 \pm 0.91$ & 3.15 & 2.7 & 13.9 & 9.95 \\
\hline Bio-waste & $28.3 \pm 2.82$ & 9.78 & 10.6 & 39.4 & 95.58 \\
\hline Small particles & $8.4 \pm 2.33$ & 8.04 & 1.2 & 22.2 & 65.10 \\
\hline Hygiene (diapers and pads) & $5.6 \pm 2.37$ & 8.24 & 0.0 & 26.3 & 67.63 \\
\hline Textile & $1.8 \pm 0.86$ & 2.99 & 0.0 & 9.8 & 8.86 \\
\hline Rubber, leather & $0.4 \pm 0.30$ & 1.06 & 0.0 & 3.7 & 1.12 \\
\hline Wood & $0.4 \pm 0.27$ & 0.95 & 0.0 & 3.3 & 0.89 \\
\hline Metal & $1.7 \pm 0.42$ & 1.44 & 0.0 & 4.3 & 2.07 \\
\hline Glass & $6.2 \pm 1.33$ & 4.62 & 0.1 & 13.0 & 21.29 \\
\hline Mineral & $5.6 \pm 2.50$ & 8.67 & 0.0 & 25.7 & 75.15 \\
\hline
\end{tabular}

$* n=12$, Confidence interval for mean $=95 \%$.

The scattering of papers' amount is heterogeneous for the whole year, as well as for the autumn and winter season, as shown by the descriptive results. The soft paper for hygiene is the paper type that significantly affects percentage apportionment of paper within the fine fraction. The percentage amount of paper increased significantly within the fine fraction, when compared to the previous research in Brocēni municipality.

The test results of the morphological composition of the coarse fraction (mass, \%) shows that paper makes $16.5 \%$, plastics $38.6 \%$, bio waste $3 \%$, fine $(<10 \mathrm{~mm}) 2 \%$, nappies $21.9 \%$, textiles $12.2 \%$, rubber and leather $2.5 \%$, wood $2 \%$, metal $0.2 \%$, glass $0.5 \%$ and inert (ceramic, stones) $0.6 \%$.

After normalization of the data and taking into account the proportions of the amount of sifted waste (Fig. 6) - in average $16 \%$ of bio-waste come into the coarse fraction. In average $84 \%$ of biowaste accumulates into the fine fraction. The results are similar to the previous research [6].

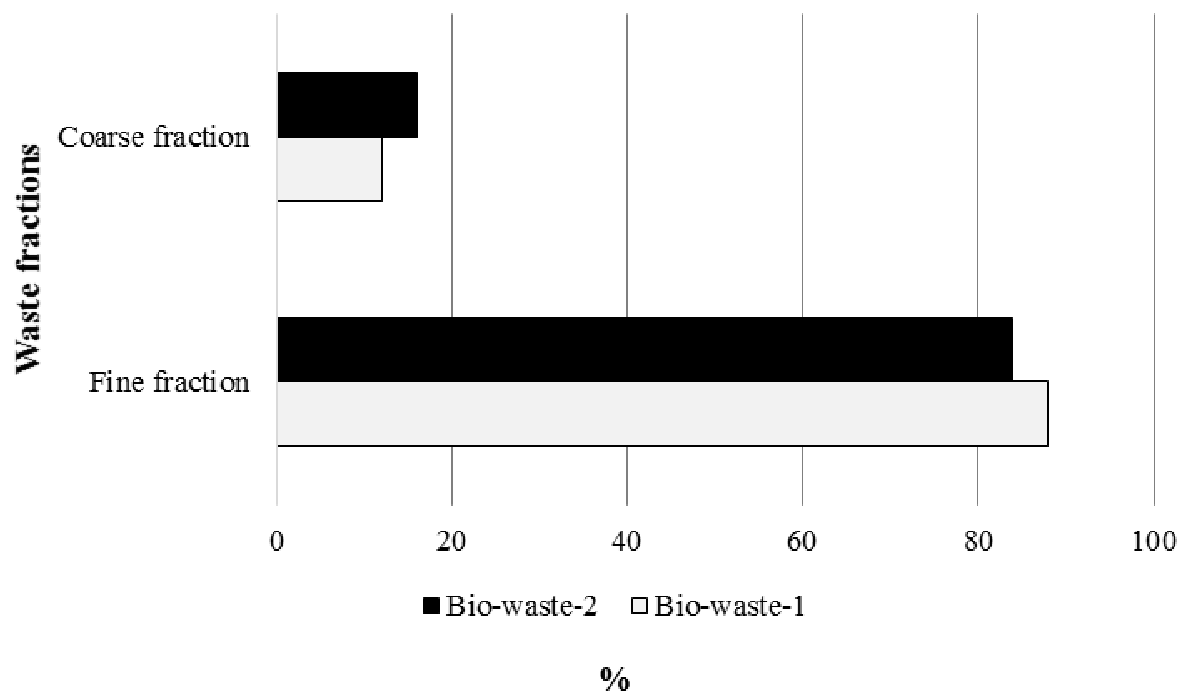

Fig. 6. Bio-waste in fractions after screening (mass, \%): bio-waste-1 - data from literature [6]; biowaste- 2 - results of the research

The moisture content was detected for the samples of the fine fraction for all seasons (Table 3). 
Average moisture content of fine fraction $(<60 \mathrm{~mm}$ ) of municipal solid waste after waste pre-treatment, $\%$

\begin{tabular}{|c|c|c|c|c|c|}
\hline Season & Average & Std. Deviation & Min & Max & Variance \\
\hline Autumn & $66.1 \pm 2.70$ & 4.67 & 60.9 & 69.9 & 21.86 \\
\hline Winter & $54.3 \pm 4.71$ & 8.15 & 45.5 & 61.6 & 66.49 \\
\hline Spring & $36.3 \pm 2.40$ & 4.16 & 31.5 & 38.8 & 17.29 \\
\hline Summer & $42.0 \pm 7.94$ & 13.75 & 33.5 & 57.9 & 189.17 \\
\hline Average per year & $49.7 \pm 4.06$ & 14.07 & 31.5 & 69.9 & 198.03 \\
\hline
\end{tabular}

The amount of moisture varies significantly between the seasons. The results show that the average moisture content of the fine fraction is from $34 \%$ to $58 \%$ in the summer season. It is similar to the previous results [6] for the summer season (43-50\%), when bio-waste was not separated at the source.

\section{Conclusions}

1. Bio-waste separation at the source reduces the mass of the fine fraction by $10-15 \%$.

2. Paper (36\%) and bio-waste $(28 \%)$ form the largest part of the fine fraction.

3. The amount of humidity of the fine fraction is high, although bio-waste was partly separated at the source.

4. Inhabitants did not separate bio-waste at the source by $100 \%$, as shown by the content of biowaste within the waste fractions, especially within the fine fraction of waste (average $28 \%$ ).

\section{Acknowledgements}

The research has been worked out by co-financial support of the European Regional Development Fund for postdoctoral project "Research of optical and energetic properties of mixed municipal solid waste material for its preparation for a recovery" No. 1.1.1.2/VIAA/1/16/221 (project agreement No. 1.1.1.2/16/I/001).

\section{References}

[1] The Waste and Resources Action Programme (WRAP): Food Waste Collection Guidance 2009, Final report [online] [26.04.2019] Available at: http://waste-prevention.gr/waste/wpcontent/uploads/2015/10/2009_Food \%20Waste \%20Collection \%20Guidance_EN.pdf

[2] Lakshmikanthan P., Sughosh P., White J., Sivakumar Babu GL.: Experimental and modelling studies on a laboratory scale anaerobic bioreactor treating mechanically biologically treated municipal solid waste. Waste Management\& Research, vol. 35, issue 7, July 2017, pp. 700-720

[3] Petrovic I.: Mini-review of the geotechnical parameters of municipal solid waste: Mechanical and biological pre-treated versus raw untreated waste. Waste Management\& Research, vol. 34, issue 9, September 2016, pp. 840-850

[4] Meirhofer M., Piringer G., Rixrath D., Sommer M., Ragossnig AM.: Implementing an advanced waste separation step in an MBT plant: assessment of technical, economic and environmental impacts. Waste Management\& Research, vol. 31, issue 10 supplement, October 2013, pp. 35-45

[5] Ministry of Environmental Protection and Regional Development of the Republic of Latvia: Assessment of Content of Municipal Solid, Hazardous and Producing Waste in Waste Management Regions (In Latvian) [online] [04.03.2019] Available at: http://www.varam.gov.lv/lat/publ/petijumi/petijumi_vide/?doc = 24933 (2017). Accessed 3 April 2018

[6] Arina D., Orupe A. Comparison of municipal solid waste characteristics after separation by star and drum screen systems. Proceedings of 4th International Conference "Civil Engineering"13", 2013, Jelgava, Latvia, Part I, pp. 318-322. 